\title{
Breast Cancer Sentinel Node Detection: An Alternative Solution for Centers Lacking Nuclear Technology
}

\author{
Mahmoud A. Alhussini ${ }^{a}$ Ahmed T. Awad ${ }^{a}$ Mohamed H. Ashour ${ }^{b}$ Ahmed Abdelateef ${ }^{a}$ \\ Haytham Fayed ${ }^{a}$
}

a Surgical Oncology Unit, Faculty of Medicine, Alexandria University, Alexandria, Egypt;

bSurgery Department, Medical Research Institute, Alexandria University, Alexandria, Egypt

\section{Keywords}

SNB - Methylene blue

\section{Summary}

Background: Sentinel lymph node (SLN) has become the gold standard for all cases with no axillary nodal metastasis. The combined radioisotope and blue dye technique is adopted in most centers. The lack of the technology for radioisotope in our institution encouraged us to study the feasibility of methylene blue (MB) for SLN detection in breast cancer patients admitted to Alexandria Surgical Oncology Unit. Methods: A total of 144 cases were subjected to SLN detection by injecting $2 \mathrm{ml}$ of MB $1 \%$. This was followed by standard axillary lymph node dissection. The safety and accuracy of MB as a tracer for detection of SLN were studied. Results: The identification rate was $93.15 \%$. The number of SLN identified ranged from 1 to 8 nodes with a mean of $1.75 \pm 1.17$. The sensitivity of MB dye technique was $96.3 \%$. The false negative rate was $3.7 \%$. The negative predictive value was $97.6 \%$ and the accuracy was $98.5 \%$. Conclusions: $\mathrm{MB}$ is a safe, reliable, cheap, and accurate alternative tracer for detection of SLN.

(c) 2016 S. Karger GmbH, Freiburg

\section{Introduction}

The status of axillary lymph nodes is the most important factor in predicting long-term survival and subsequently affects the decision for adjuvant therapy in some cases of breast cancer [1]. However, the aim and extent of axillary lymph node dissection (ALND) for early breast cancer is a topic of great interest among clinicians treating breast carcinoma [2]. ALND, as a means for achieving local disease control, carries a risk of complications such as seroma, infection and lymphedema [3-5]. The sentinel lymph node (SLN) concept evolved from the principle that a primary tumor is drained by an afferent lymphatic channel that courses to the first 'sentinel' lymph node in a specific regional lymphatic basin [6]. SLN biopsy can accurately stage the axilla in early breast cancer with much less morbidity and complications than ALND [7-9]. During surgery the SLN can be localized by radiotracers (using gamma probes), blue dye, or both [10]. The lack of continuous supply of the radioactive tracer in our institution and the commercial availability of methylene blue (MB) lead us to study the use of this blue dye alone for SLN detection. MB was the only commercially available blue dye available in our institution. MB is methylthionine hydrochloride and is a dark green crystalline compound that turns dark blue in solution [11].

The safety of MB dye for use has been demonstrated through its wide use through the medical practice. As a diagnostic procedure MB has been used for delineation of fistulous tracts and Barrett's esophagus [12, 13]. Moreover, it has been therapeutically used in the treatment of methemoglobinemia and hemorrhagic shock [14]. Based on the previous data of safety of $\mathrm{MB}$ and on the numerous data in the literature [15-19] about the feasibility of SLN detection by that dye, we decided to start our own experience for SLN detection using MB dye as a sole, safe, cheap, and available tracer.

\section{Patients and Methods}

The study included 144 female patients with breast carcinoma admitted to the Surgical Oncology Unit, Alexandria Faculty of Medicine, in the period from July 2012 to March 2013. The study was approved by the Ethical Committee of Alexandria university faculty of medicine. All patients included in the study signed an informed consent form with full details about the study.

\section{KARGER}

(๑) 2016 S. Karger GmbH, Freiburg
Dr. Mahmoud A. Alhussini 
Table 1. Patient and tumor characteristics

\begin{tabular}{|c|c|c|}
\hline Characteristic & $\mathrm{n}$ & $\%$ \\
\hline \multicolumn{3}{|l|}{ Demographic patient data } \\
\hline Mean age, years (range) & $53.73(25-84)$ & \\
\hline$<50$ & 61 & 42.4 \\
\hline$\geq 50$ & 83 & 57.6 \\
\hline \multicolumn{3}{|l|}{ Menopausal status } \\
\hline Premenopausal & 64 & 44.4 \\
\hline Postmenopausal & 80 & 55.6 \\
\hline \multicolumn{3}{|l|}{ Surgical intervention } \\
\hline BCS & 52 & 35.6 \\
\hline Mastectomy & 94 & 64.4 \\
\hline \multicolumn{3}{|l|}{ Tumor characteristics } \\
\hline \multicolumn{3}{|l|}{ Tumor type } \\
\hline Ductal & 98 & 67.1 \\
\hline Lobular & 7 & 4.8 \\
\hline Mixed & 41 & 28.1 \\
\hline \multicolumn{3}{|l|}{ Tumor size, $\mathrm{cm}$} \\
\hline$<2$ & 38 & 26.0 \\
\hline$<2-<5$ & 103 & 70.6 \\
\hline$\geq 5$ & 5 & 3.4 \\
\hline \multicolumn{3}{|l|}{ Tumor grade } \\
\hline 1 & 18 & 12.3 \\
\hline 2 & 106 & 72.6 \\
\hline 3 & 22 & 15.1 \\
\hline \multicolumn{3}{|l|}{ ER status } \\
\hline $\mathrm{ER}+\mathrm{ve}$ & 112 & 76.7 \\
\hline ER -ve & 34 & 23.3 \\
\hline \multicolumn{3}{|l|}{ Her2 neu status } \\
\hline Her2 neu +ve & 43 & 29.5 \\
\hline Her2 neu -ve & 103 & 70.5 \\
\hline \multicolumn{3}{|c|}{ Lymph nodes identification } \\
\hline Failure & 10 & 6.8 \\
\hline Identification & 136 & 93.2 \\
\hline
\end{tabular}

$\mathrm{BCS}=$ Breast conserving surgery, $\mathrm{ER}=$ estrogen receptor.

All patients included in the study had no suspicious axillary lymph nodes both by clinical examination and ultrasonography. SLN detection was done by injecting $1.8 \mathrm{ml}$ of $\mathrm{MB}$ dye in the sub-areolar region just after induction of anesthesia and tapping massage was done for $8-10 \mathrm{~min}$. The axilla was then explored via a small incision at the lowest hairline. SLNs were identified by being blue stained or having blue lymphatic entering it or both together. Formal level I and level II axillary dissection was done in order to assess that the harvested SLN truly represents the axillary lymph node status.

\section{Results}

This study included 144 patients with 2 of them suffering of bilateral disease. Hence, 146 procedures were done. The age ranged from 25 to 84 years with a mean of $53.73 \pm 12.15$ years. Premenopausal cases constituted $44.4 \%$ ( 64 cases) of the whole studied group.

The axillary lymph node status, after standard levels I and II dissection was found negative in $100(68.5 \%)$ patients and positive in the remaining 46 patients (31.5\%). The number of nodes dissected ranged from 8 to 18 nodes with a mean of $11.81 \pm 2.40$ (table 1 ).

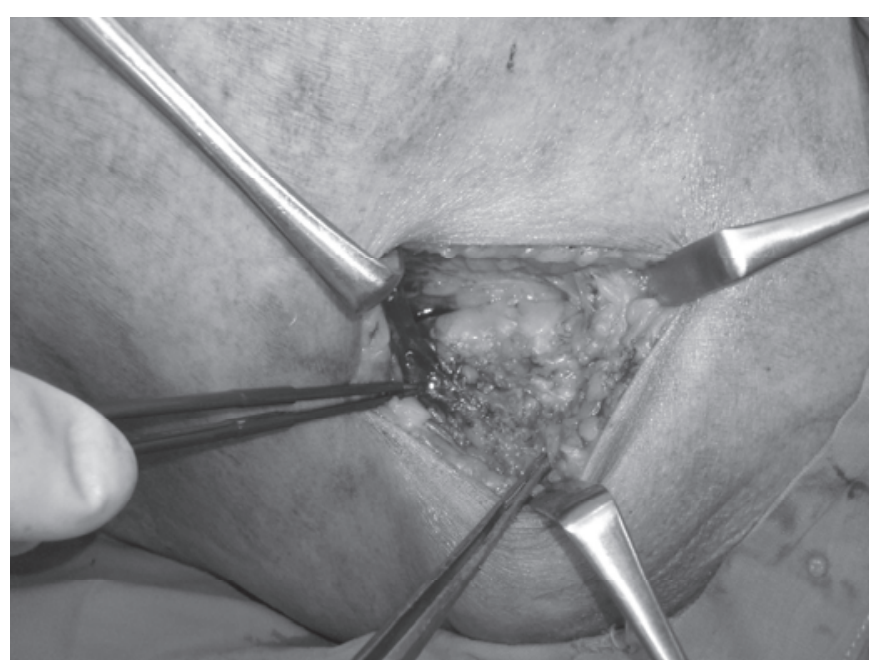

Fig. 1. Intraoperative identification of the SLN.

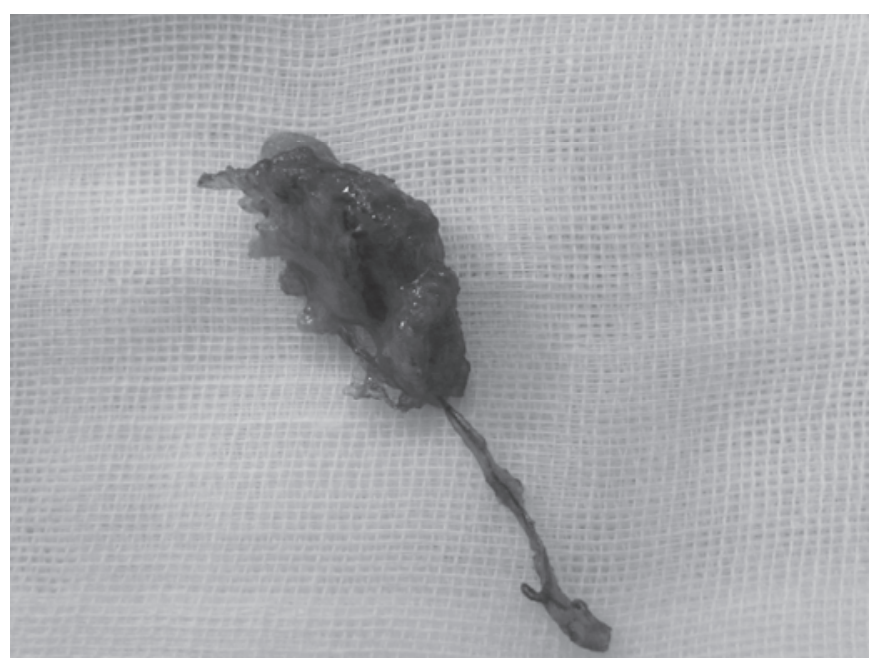

Fig. 2. SLN with sentinel lymph vessel after being harvested.

The procedure failed to identify the SLN 10 times and succeeded 136 times (fig. 1, 2). Thus, the identification rate was 93.15\%. The number of SLN identified ranged from 1 to 8 nodes with a mean of $1.75 \pm 1.17$. The SLN was negative in $84(61.8 \%)$ patients and was affected with metastasis in the other 52 (38.2\%) patients.

Of the 10 cases in which the technique failed to identify the SLN, 8 cases were found to have axillary lymph node involvement with metastasis while the remaining 2 were free.

To correlate the state of the SLN with the state of the axilla, we excluded the 10 cases in which the technique failed. Thus, in 136 cases of identified SLN, the sentinel and axillary nodes status coincided in 118 patients. Both the SLN and axillary nodes were free of metastases in 82 patients (60.3\%; table 2$)$ and both were found involved in 36 patients (26.5\%). The SLN was the only site of metastasis encountered with no other positive nodes in 16 patients (11.8\%). 2 patients showed a false negative result. In these patients, the axilla was found involved with micrometastases that were not detected intraoperatively by frozen section. In our study, the sensi- 
Table 2. Relation between lymph state and axillary lymph $(\mathrm{n}=136)$

\begin{tabular}{|c|c|c|c|c|c|c|c|}
\hline \multirow[t]{3}{*}{ SLN } & \multicolumn{4}{|c|}{ ALND specimen } & \multirow[t]{3}{*}{ Sensitivity } & \multirow[t]{3}{*}{ Specificity } & \multirow[t]{3}{*}{ Accuracy } \\
\hline & \multicolumn{2}{|c|}{ negative $(\mathrm{n}=98)$} & \multicolumn{2}{|c|}{ positive $(\mathrm{n}=38)$} & & & \\
\hline & $\mathrm{n}$ & $\%$ & $\mathrm{n}$ & $\%$ & & & \\
\hline Negative & 82 & 60.3 & 2 & 1.5 & 94.74 & 83.67 & 86.76 \\
\hline Positive & 16 & 11.8 & 36 & 26.5 & & & \\
\hline $\mathrm{p}$ value & \multicolumn{4}{|c|}{$<0.001^{*}$} & & & \\
\hline
\end{tabular}

$\mathrm{p}$ value for chi-square test for comparing between the 2 studied group.

${ }^{*}$ Statistically significant at $\mathrm{p} \leq 0.05$. tivity of $\mathrm{MB}$ dye technique was $96.3 \%$. The false negative rate, which is considered the most important figure in the study, was $3.7 \%$. The negative predictive value was $97.6 \%$ and the accuracy was $98.5 \%$.

As regards the side effects of $\mathrm{MB}, 4$ patients (2.8\%) reported bluish or greenish discoloration of urine in the first $24 \mathrm{~h}$ following surgery. 1 patient with bilateral breast cancer developed superficial gangrene involving both areolas. This patient was suffering from chronic dryness of the skin and may be considered a wrongly selected case. She was managed by debridement and frequent dressing but was lost in the follow-up period. We did not report any case with localized allergy or systemic anaphylaxis to MB.

\section{Discussion}

Combining radioactive colloid with blue dye injection is the best way to assess SLNB in breast cancer [20,21].

Many institutions and hospitals in developing countries - including ours - still routinely do complete ALND. This is partly attributed to the belief that axillary dissection, although falsely, gives the impression of security and partly to the lack of access or finance to provide isotopes and gamma probes.

Therefore, we aimed at evaluating the accuracy of $\mathrm{MB}$ alone in assessing the SLN and axillary status.

The identification rate of the SLN in our study was $93.15 \%$. Kern [22] reported an identification rate of $97.5 \%$ and in the work by Golshan and Nakhlis [19] the identification rate was $96.5 \%$. Both Kern [22] and Golshan and Nakhlis [19] used the sub-areolar isolated blue dye technique with the difference that Kern [22] used patent blue dye while Golshan and Nakhlis [19] used MB dye. Mokbel and Mostafa [23] also used the sub-areolar injection of MB dye in a study including 35 patients and the identification rate was 97\% (34 patients). He reported a failure in a 77-year-old woman who had metastasis in 5 out of 13 lymph nodes dissected. Moreover, he reported no side effects of MB apart from temporary tattooing of the skin.

Varghese et al. [18] used the MB peritumorally for the identification of SLN. The identification rate was $96.5 \%$. They attributed the rate of identification to the number of procedures performed.
Thus, we state that the built up experience of the surgeon plays a major role both in the time and accuracy of identification.

The number of SLN identified ranged from 1 to 8 nodes with mean of $1.75 \pm 1.17$. Radovanovic et al. [24] reported similar results in both groups of their study as the mean number of SLN was 1.7 and 1.6. This is consistent with the results of Mokbel and Mostafa [23] and Anan et al. [25] who mentioned that the mean number of SLN identified was 2 and 1.6, respectively. The latter authors interestingly studied double mapping with sub-areolar blue dye and peritumoral green dye.

Giuliano et al. [26] showed a false negative rate of $12 \%$. He stated that misidentification of blue stained fat as a SLN was an important cause of false negative rate but introduction of frozen section solved the problem and the false negative rate became $0 \%$ in his next series [27] 3 years later.

Kern [22] showed a false negative rate of $0 \%$ while Guenther et al. [28] showed a false negative rate of $9.7 \%$ and he stated that false negative rate was at early phase of the study due to lack of experience.

Veronesi et al. [9] had a false negative rate of 5\%, while Tafra et al. [29] had a $0 \%$ false negative rate. This was explained by the usage of combined technique (using blue dye and radioactive colloid technique) for identification of the SLNs, and also the use of immunohistochemical stains in revision of SLN for patients with negative SLNs and positive non-SLN metastasis.

In the current study, the false negative rate was $3.7 \%$ which we think is quite acceptable and comparable to the results of other methods.In the present study, we stressed upon the negative state of axillary lymph nodes by clinical examination as well as by imaging procedures. Therefore, the use of MB alone as a sole tracer for SLN detection is a safe, simple, and reliable technique. The built-up experience is essential in overcoming the challenge of finding the target node(s).

\section{Disclosure Statement}

All authors have no financial or personal relationships with other people or organizations that could inappropriately influence (bias) their work, that is, no conflict of interest among any of the authors. 


\section{References}

1 Fisher B, Bauer M, Wickerham DL, et al: Relation of number of positive axillary nodes to the prognosis of patients with primary breast cancer. An NSABP update. Cancer 1983;52:1551-1557.

2 Robinson D, Senofsky GM, Ketcham AS: Role and extent of lymphadenectomy for early breast cancer. Semin Surg Oncol 1992;8:78-82.

3 Yeoh EK, Denham JW, Davies SA, Spittle MF: Primary breast cancer. Complications of axillary management. Acta Radiol Oncol 1986;25:105-108.

4 Lotze MT, Duncan MA, Gerber LH, Woltering EA Rosenberg SA: Early versus delayed shoulder motion following axillary dissection: a randomized prospective study. Ann Surg 1981;193:288-295.

5 Ivens D, Hoe AL, Podd TJ, Hamilton CR, Taylor I, Royle GT: Assessment of morbidity from complete axillary dissection. Br J Cancer 1992;66:136-138.

6 Wong JH, Cagle LA, Morton DL: Lymphatic drainage of skin to a sentinel lymph node in a feline model. Ann Surg 1991;214:637-641.

7 Lyman GH, Giuliano AE, Somerfield MR, et al: American society of clinical oncology guideline recommendations for sentinel lymph node biopsy in early-stage breast cancer. J Clin Oncol 2005;23:7703-7720.

8 Schwartz GF, Giuliano AE, Veronesi U: Proceedings of the consensus conference on the role of sentinel lymph node biopsy in carcinoma of the breast, April 19-22, 2001, Philadelphia, Pennsylvania. Cancer 2002;94: 2542-2551.

9 Veronesi U, Paganelli G, Galimberti V, et al: Sentinelnode biopsy to avoid axillary dissection in breast cancer with clinically negative lymph-nodes. Lancet 1997; 349:1864-1867.

10 Syme DB, Collins JP, Mann GB: Comparison of blue dye and isotope with blue dye alone in breast sentinel node biopsy. ANZ J Surg 2005;75:817-821.

11 Dollery C: Therapeutic Drugs, ed 2. New York, Churchill Levingstone, 1998.
Hanash KA, Al Zahrani $\mathrm{H}$, Mokhtar AA, Aslam M: Retrograde vaginal methylene blue injection for localization of complex urinary fistulas. J Endourol 2003;17: 941-943.

13 Duncan MB, Horwhat JD, Maydonovitch CL, Ramos F, Colina R, Gaertner E, et al: Use of methylene blue for detection of specialized intestinal metaplasia in GERD patients presenting for screening upper endoscopy. Dig Dis Sci 2005;50:389-393.

14 Jeroukhimov I, Weinbroum A, Ben-Avraham R, AbuAbid S, Michowitz M, Kluger Y: Effect of methylene blue on resuscitation after haemorrhagic shock. Eur J Surg 2001;167:742-747.

15 Simmons RM, Smith SM, Osborne MP: Methylene blue dye as an alternative to isosulfan blue dye for sentinel lymph node localization. Breast J 2001;7:181-183.

16 Eldrageely K, Vargas MP, Khalkhali I, Venegas R, Burla M, Gonzalez KD, et al: Sentinel lymph node mapping of breast cancer: a case-control study of methylene blue tracer compared to isosulfan blue. Am Surg 2004;70:872-875.

17 Nour A: Efficacy of methylene blue dye in localization of sentinel lymph node in breast cancer patients. Breast J 2004;10:388-391.

18 Varghese P, Abdel-Rahman AT, Akberali S, Mostafa A, Gattuso JM, Carpenter R: Methylene blue dye - a safe and effective alternative for sentinel lymph node localization. Breast J 2008;14:61-67.

19 Golshan M, Nakhlis F: Can methylene blue only be used in sentinel lymph node biopsy for breast cancer? Breast J 2006;12:428-430.

20 Waddington WA, Keshtgar MR, Taylor I, Lakhani SR, Short MD, Ell PJ: Radiation safety of the sentinel lymph node technique in breast cancer. Eur J Nucl Med 2000;27:377-391

21 William JG, William CW: Advances in Breast Cancer Management. New York, Springer Science, 2008
22 Kern KA: Sentinel lymph node mapping in breast cancer using subareolar injection of blue dye. J Am Coll Surg 1999;189:539-545.

23 Mokbel K, Mostafa A: The Role of Subareolar Blue Dye in Identifying the Sentinel Node in Patients with Invasive Breast Cancer. Current Medical Research and Opinion. 2001. http://www.medscape.com/viewarticle/ 407818 (cited June 25, 2009).

24 Radovanovic Z, Golubovic A, Plzak A, Stojiljkovic B, Radovanovic D: Blue dye versus combined blue dyeradioactive tracer technique in detection of sentinel lymph node in breast cancer. Eur J Surg Oncol 2004; 30:913-917.

25 Anan K, Mitsuyama S, Kuga H, Saimura M, Tanabe Y, Suehara N, Matsunaga H, Nishihara K, Abe Y, Iwashita T, Ihara T, Tamae K, Ono M, Toyoshima S: Double mapping with subareolar blue dye and peritumoral green dye injections decreases the false-negative rate of dye-only sentinel node biopsy for early breast cancer: 2 -site injection is more accurate than 1-site injection. Surgery 2006; 139:624-629.

26 Giuliano AE, Kirgan DM, Guenther JM, Morton DL: Lymphatic mapping and sentinel lymphadenectomy for breast cancer. Ann Surg 1994;220:391-398; discussion 398-401.

27 Giuliano AE, Jones RC, Brennan M, Statman R: Sentinel lymphadenectomy in breast cancer. J Clin Oncol 1997;15:2345-2350.

28 Guenther JM, Krishnamoorthy M, Tan LR: Sentinel lymphadenectomy for breast cancer in a community managed care setting. Cancer J Sci Am 1997;3:336340.

29 Tafra L, Lannin DR, Swanson MS, Van Eyk JJ, Verbanac KM, Chua AN, et al: Multicenter trial of sentinel node biopsy for breast cancer using both technetium sulfur colloid and isosulfan blue dye. Ann Surg 2001; 233:51-59. 